\title{
Impact of immune reconstitution inflammatory syndrome on antiretroviral therapy adherence
}

\author{
This article was published in the following Dove Press journal: \\ Patient Preference and Adherence \\ II December 2012 \\ Number of times this article has been viewed
}

\author{
Jean B Nachega ${ }^{1,2,4}$ \\ Chelsea Morroni' \\ Richard E Chaisson ${ }^{2-4}$ \\ Rene Goliath' \\ Anne Efron ${ }^{4}$ \\ Malathi Ram² \\ Gary Maartens' \\ 'University of Cape Town, Department \\ of Medicine, Division of Clinical \\ Pharmacology, Cape Town, South \\ Africa; ${ }^{2}$ Johns Hopkins University, \\ Bloomberg School of Public Health, \\ Departments of International Health \\ and Epidemiology, Johns Hopkins \\ University, School of Medicine, \\ Department of Medicine, Division \\ of Infectious Diseases, ${ }^{4}$ Johns Hopkins \\ University, Center for Tuberculosis \\ Research, Baltimore, Maryland, USA
}

Correspondence: Jean B Nachega Johns Hopkins University, Bloomberg School of Public Health, Department of International Health, Global Disease Epidemiology and Control Program, 615 N Wolfe Street, Suite W503I, Baltimore, MD 2I 205, USA

Tel +l 4109552378

Fax +I 4105026733

Email jnachega@jhsph.edu
Objective: We determined the impact of immune reconstitution inflammatory syndrome (IRIS) on antiretroviral therapy (ART) adherence in a cohort of 274 human immunodeficiency virus (HIV)-infected South African adults initiating ART.

Methods: We carried out a secondary analysis of data from a randomized controlled trial of partially supervised ART in Cape Town, South Africa. Monthly pill count adherence, viral suppression (HIV viral load $<50 \mathrm{c} / \mathrm{mL}$ ), and IRIS events were documented. Poisson regression was used to identify variables associated with ART adherence below the median in the first 6 months of ART.

Results: We enrolled 274 patients: 58\% women, median age 34 years, median CD4 count 98 cells $/ \mu \mathrm{L}, 46 \%$ World Health Organization clinical stage IV, and $40 \%$ on treatment for tuberculosis (TB). IRIS and TB-IRIS developed in $8.4 \%$ and $6.6 \%$ of patients, respectively. The median cumulative adherence at 6 months for those with an IRIS event vs no IRIS was $95.5 \%$ vs $98.2 \%(P=0.04)$. Although not statistically significant, patients developing IRIS had a lower 6 -month viral load suppression than those without IRIS ( $68 \%$ vs $80 \%, P=0.32)$. ART adherence below the median of $98 \%$ was independently associated with alcohol abuse (relative risk [RR] 1.5; 95\% confidence interval [CI] 1.2-1.9; $P=0.003)$ and IRIS events (RR 1.7; 95\% CI $1.2-2.2 ; P=0.001)$.

Conclusion: Although IRIS events were associated with slightly lower adherence rates, overall adherence to ART remained high in this study population. Concerns about IRIS should not deter clinicians from early ART initiation.

Keywords: ART, adherence, TB, HIV/AIDS, IRIS

Antiretroviral therapy (ART) improves outcomes of human immunodeficiency virus (HIV)-related tuberculosis (TB), ${ }^{1,2}$ and results from the Starting Antiretroviral Therapy at Three Points in Tuberculosis (SAPIT), Cambodian Early versus Late Introduction of Antiretrovirals (CAMELIA), and The AIDS Clinical Trial Group (ACTG) Study 5221 (STRIDE) randomized controlled trials showed that early ART initiation (within the first 2 months of anti-TB therapy) is associated with lower morbidity and mortality in TB-HIV co-infected patients, despite being associated with a two to threefold increase in immune reconstitution inflammatory syndrome (IRIS) events. ${ }^{3-5}$ Whether IRIS events related to TB or other diseases affect ART adherence is largely unknown.

We measured the frequency and timing of IRIS events in a cohort of HIV-infected South African adults initiating ART and measured the association of these events with subsequent ART adherence. 


\section{Methods}

\section{Study design, setting, and patient enrollment}

This was a secondary analysis of a randomized controlled trial evaluating the impact of patient-nominated treatment supporters with partial directly observed administration of ART (DOTART) on ART adherence, HIV viral load, and CD4+T-cell count. This trial, which was reported in detail elsewhere, ${ }^{6}$ showed that the presence of a patient-nominated supporter was not associated with improved ART adherence or virologic suppression but was associated with increased survival (a secondary endpoint).

The study was conducted at GF Jooste Hospital, Cape Town, South Africa, a public sector, secondary-level, peri-urban hospital with more than 12,000 admissions annually, about $20 \%$ of which are for infectious diseases (61\% HIV). Government-funded comprehensive ART care is provided free of charge at primary care clinics and in the hospital clinic.

Eligibility criteria in the parent study were: (1) male or nonpregnant female 18 years of age or older; (2) HIV infection documented by two serologic tests; (3) eligible to start ART according to South African guidelines at the time ${ }^{8} \mathrm{CD} 4+\mathrm{T}$-cell count $\leq 200$ cells $/ \mu \mathrm{L}$ or World Health Organization clinical stage IV disease; (4) living in the study catchment area; and (5) willing to disclose HIV status to a treatment supporter. Patients were excluded if they had: (1) prior ART use; (2) life expectancy less than 6 months; (3) Karnofsky Performance Score ${ }^{9}$ less than 60; (4) transaminases more than five times the upper limit of normal; or (5) history of single-dose nevirapine for prevention of mother to child transmission of HIV infection.

\section{Antiretroviral therapy and anti- tuberculosis regimens}

Standard first-line anti-TB treatment regimen was given per South African TB guidelines, ${ }^{8}$ administered 5 days per week, and directly observed during the 2-month intensive phase. The initial ART regimen consisted of stavudine, lamivudine, and efavirenz. ${ }^{7}$ For women not willing to use contraception, nevirapine was substituted for efavirenz. Regimen changes were permitted following South African HIV guidelines. ${ }^{7}$ All patients were followed monthly for clinical evaluation, pill counts, and ART adherence counseling as needed.

\section{Immune reconstitution inflammatory syndrome case definition}

We retrospectively applied standardized definitions for tuberculosis and cryptococcal-associated IRIS, which have been proposed by the International Network for the Study of HIV-Associated IRIS (INSHI), for use in resource-limited settings. ${ }^{10,11}$ Other events, such as herpes zoster virus (HZV) or herpes simplex virus (HSV), were considered as IRIS if they appeared within 3 months of ART initiation and had documented decreased viral load and/or immune reconstitution as evidenced by CD4+ T-cell count as per previously published reports. ${ }^{12}$

\section{Regulatory approvals}

The study was approved by the committees on the Protection of Human Individuals or Research Ethics Boards from Johns Hopkins University School of Medicine, Baltimore, Maryland, and the University of Cape Town, Cape Town, South Africa.

\section{Data analysis}

We measured the proportions of patients with any IRIS and TB-IRIS events during the first 6 months of follow-up. We calculated ART adherence as the median cumulative monthly pill count over the same time period. Chi-square tests and Wilcoxon rank sum tests were used for comparisons of proportions and medians, as appropriate. We used log-binomial regression for both univariate and multivariate regression; this was followed by Poisson regression with robust variance estimation since the log-binomial model failed to converge. Our rationale for not using a logistic regression method is that odds ratios are likely to be biased (inflated) estimates of the relative risk, and thus misleading, when the outcome is common. Variables were included in the multivariate model if they were associated with adherence or IRIS events in univariate analysis $(P \leq 0.2)$. Associations with adherence were considered statistically significant in the multivariate regression model if $P \leq 0.05$. Baseline alcohol abuse was evaluated by the validated, short, four-question, Cut down, Annoyed by criticism, Guilty about drinking, Eye-opener drinks (CAGE) screening questionnaire that diagnoses alcohol problems over a lifetime. A total score of two or higher (answering "yes" to two or more questions) indicates a problem with alcohol. ${ }^{13}$ Data analysis was performed using STATA 11 (Stata Corporation, College Station, TX, USA).

\section{Results}

\section{Baseline characteristics and frequency of IRIS events}

The baseline characteristics of patients with and without IRIS events are shown in Table 1. Overall, patients had advanced HIV disease, with $46 \%$ having AIDS and a median CD4+ 
Table I Patient clinical and demographic characteristics at enrollment

\begin{tabular}{|c|c|c|c|c|}
\hline Variable & $\begin{array}{l}\text { IRIS } \\
n=23\end{array}$ & $\begin{array}{l}\text { No IRIS } \\
n=25 I\end{array}$ & $\begin{array}{l}\text { Total } \\
n=274\end{array}$ & $P$-value \\
\hline Median age in years (range) & $32(29-44)$ & $35(30-4 I)$ & $34(18-74)$ & 0.52 \\
\hline Enrolled in DOT-ART arm of parent RCT, $n(\%)$ & $12(52 \%)$ & 125 (48\%) & 137 (50\%) & 0.83 \\
\hline Female, $n(\%)$ & $13(57 \%)$ & $145(58 \%)$ & $158(58 \%)$ & 0.91 \\
\hline \multicolumn{5}{|l|}{ WHO clinical stage, $n(\%)$} \\
\hline I-III & $10(43 \%)$ & 138 (55\%) & I 48 (54\%) & 0.29 \\
\hline IV & $13(57 \%)$ & $113(45 \%)$ & $126(46 \%)$ & \\
\hline Alcohol abuse (CAGE+), n (\%) & $5(22 \%)$ & $42(17 \%)$ & $47(17 \%)$ & 0.54 \\
\hline Median (IQR) CD4+ T-cell count (cells $/ \mu \mathrm{L}$ ) & $78(37-112)$ & $99(45-150)$ & $98(43-148)$ & 0.09 \\
\hline \multicolumn{5}{|l|}{ Type of NNRTI } \\
\hline Efavirenz & $19(83 \%)$ & 207 (83\%) & $226(83 \%)$ & 0.92 \\
\hline Nevirapine & $4(17 \%)$ & $4 \mid(I 7 \%)$ & $45(17 \%)$ & \\
\hline Median (IQR) Log 10 HIV-I RNA & $5.0(4.5-5.4)$ & $5.0(4.6-5.4)$ & $5.0(4.6-5.4)$ & 0.94 \\
\hline
\end{tabular}

T-cell count of 98 cells/ $\mu \mathrm{L}$ (Interquartile range [IQR] 93-148). Twenty-three patients out of 274 (8.4\%) experienced an IRIS event (one patient with genital HSV- and TB-IRIS, one with HZV-IRIS, three with paradoxical cryptococcal meningitisIRIS, and 18 with TB-IRIS, which included 14 paradoxical TB-IRIS cases and four unmasking TB-IRIS cases). Overall, $6.6 \%$ of patients $(n=18)$ developed any TB-IRIS, and $9.8 \%$ of patients on TB treatment at ART initiation (11 of 112) developed paradoxical TB-IRIS. The median (IQR) time to any IRIS event from ART initiation was 15 days (7-42), to any TB-IRIS was 14 days (6-24.5), and to paradoxical TB-IRIS in those on TB treatment at ART initiation was 9 days (3-18). In univariate analysis, IRIS events were associated with a nonsignificant lower baseline median (IQR) CD4+ T-cell count (78 [37-112] vs 99 [45-150]; $P=0.09$ ) and earlier ART initiation after commencing TB treatment (proportion initiating ART within 2 months of starting TB chemotherapy 0.83 vs $0.58 ; P=0.09$ ). IRIS events were not associated with type of non-nucleoside reverse transcriptase inhibitor $(8.1 \%$ of those on efavirenz versus $8.9 \%$ of those on nevirapine experienced an IRIS event; $P=0.9$ ).

\section{ART adherence, immunologic, virologic, and clinical outcomes}

The median (IQR) cumulative pill count adherence at 6 months for those with an IRIS event was 95.5\% (91.4-97.8) vs 98.2\% (94.6-99.5) for those with no IRIS $(P=0.04)$. Seventy-eight percent of patients with an IRIS event had 6-month adherence below the median adherence of $98 \%$ compared to $44 \%$ of those without an IRIS event $(P=0.006)$. Median absolute change in CD4+ T-cell count (IQR) from baseline to 6 months in those with and without an IRIS event was an increase of 130 (44-222) and 134 (58-217) cells/ $\mu \mathrm{L}$, respectively $(P=0.98)$. Eighty percent of patients without an IRIS event compared with $68 \%$ of those with an IRIS event had an HIV viral load $<50 \mathrm{c} / \mathrm{mL}$ at 6 months (relative risk [RR] 0.85, 95\% confidence interval $[\mathrm{CI}] 0.62-1.16 ; P=0.32)$. There were five hospital admissions (all TB-IRIS cases), but no documented fatal outcomes related to any of the IRIS events. In a multivariate Poisson regression model, alcohol abuse (RR 1.5, 95\% CI 1.2-1.9; $P=0.003$ ) and having any IRIS event (RR 1.7, 95\% CI 1.2-2.2; $P=0.001$ ) were independently and significantly associated with ART adherence below the median of $98 \%$ (Table 2).

\section{Discussion}

In this study of South African adults initiating ART, we found that 6-month adherence rates were high (median 98\%) but that having an IRIS event was associated with moderately lower adherence (median 95\%). Although this observed difference in median ART adherence is unlikely to be of any clinical significance, it is worth noting that patients with IRIS events also experienced poorer virologic suppression at 6 months, although the difference was not statistically significant, raising the possibility of low statistical power to account for such nonsignificance. IRIS events may reduce ART adherence either because of the resulting morbidity or the erosion of patient confidence in the efficacy of ART.

ART adherence rates observed in this trial are similar to those in the SAPIT trial (97\%), ${ }^{3}$ suggesting that the high pill burden necessary to treat both HIV and TB does not affect ART adherence. However, ART adherence stratified by IRIS status was not reported in SAPIT, leaving open the question of whether IRIS events (rather than pill burden) might be 
Table 2 Univariate and multivariate factors associated with ART adherence below the median

\begin{tabular}{|c|c|c|c|c|}
\hline Variable & $\begin{array}{l}\text { Univariate RR } \\
(95 \% \mathrm{Cl})\end{array}$ & $P$-value & $\begin{array}{l}\text { Multivariate RR } \\
(95 \% \mathrm{Cl})\end{array}$ & $P$-value \\
\hline \multicolumn{5}{|l|}{ Age (years) } \\
\hline$<40$ & 1.00 & & & \\
\hline$\geq 40$ & I.I5 (0.87-I.5I) & 0.34 & N/A & N/A \\
\hline \multicolumn{5}{|l|}{ Sex } \\
\hline Male & 1.0 & & & \\
\hline Female & $1.02(0.77-1.34)$ & 0.90 & N/A & N/A \\
\hline \multicolumn{5}{|c|}{ WHO clinical stage } \\
\hline Stage I-III & 1.00 & & & \\
\hline Stage IV & $1.09(0.82-1.43)$ & 0.70 & N/A & N/A \\
\hline \multicolumn{5}{|c|}{ Alcohol abuse (CAGE+) } \\
\hline No & 1.00 & & & \\
\hline Yes & $1.61(1.24-2.10)$ & 0.003 & $1.51(1.15-1.99)$ & 0.003 \\
\hline \multicolumn{5}{|l|}{ IRIS event } \\
\hline No & 1.00 & & & \\
\hline Yes & $1.76(1.31-2.34)$ & 0.007 & $1.65(1.22-2.23)$ & 0.001 \\
\hline \multicolumn{5}{|c|}{ CD4+ T-cell count (cells/ $\mu \mathrm{L})$} \\
\hline$\geq 100$ & 1.00 & & & \\
\hline$<100$ & $1.12(0.85-1.47)$ & 0.43 & $0.90(0.69-1.18)$ & 0.45 \\
\hline \multicolumn{5}{|c|}{$\log _{10}$ HIV-I RNA (copies/mL) } \\
\hline$<5.0$ & 1.00 & & & \\
\hline$\geq 5.0$ & I.08 (0.83-I.42) & 0.60 & N/A & N/A \\
\hline
\end{tabular}

Abbreviations: RR, relative risk; $\mathrm{Cl}$, confidence interval; N/A, not applicable; CAGE+, Cut down, Annoyed by criticism, Guilty about drinking, Eye-opener drinks questionnaire; IRIS, immune reconstitution inflammatory syndrome; HIV, human immunodeficiency virus.

associated with lower mortality. No ART adherence data were reported from the CAMELIA and STRIDE trials. In these three trials, similar proportions of viral suppression at 24 weeks were achieved among study participants in the earlier ART initiation group versus participants for whom ART was delayed after the initiation of TB treatment. This suggests that ART nonadherence events did not have a significant impact on virologic outcomes; however, virologic data stratified by IRIS events were not reported. ${ }^{3-5}$

Most of the IRIS events in this study were of minor or moderate morbidity and mortality, in agreement with other previously published reports. ${ }^{14-16}$ Five of the 18 TB-IRIS cases were admitted to hospital for an average of 1 week, and there were no fatal outcomes related to any of the IRIS events. Of note, if ART was discontinued at home, it was re-administrated during inpatient stay from patient's original ART stock. Therefore, it is unlikely that hospital admissions of these few IRIS cases could have a significant impact on the pill count adherence data.

Given the clear mortality benefit to early ART initiation in TB-HIV co-infected patients and the overall high rates of adherence seen both here and in SAPIT, concern about nonadherence to ART due to IRIS events should not deter clinicians from early ART initiation. Rather, patients experiencing IRIS events may be appropriate targets for additional ART adherence support in the first 6 months after ART initiation. It is important that clinicians counsel patients starting ART beforehand on the possibility that an IRIS event may occur and that it should not be viewed as a failure of ART and/or TB treatment. There is also a need for further research to evaluate interventions to prevent TB-IRIS in high TB-HIV endemic settings. ${ }^{17}$

While informative, limitations of this study are the relatively small number of IRIS events and as a consequence a limited statistical power to detect significance for some of our findings. Therefore, future research that includes larger IRIS events should be undertaken to confirm our findings. In addition, the high overall rates of adherence and limited number of IRIS events limited our ability to consider other meaningful ART adherence cut points (eg, 80\%, 90\%). Finally, the sensitivity of pill count to detect nonadherence could be questioned. However, to date there are no established gold standard tools to monitor adherence since each measurement method has its own strengths and weaknesses. ${ }^{18}$

\section{Conclusion}

ART adherence was excellent (>95\%) in this study, regardless of whether IRIS events occurred. Thus, concerns about IRIS 
should not deter clinicians from early ART initiation, but close ART adherence monitoring is warranted as for any HIV-infected patient, irrespective of an IRIS event.

\section{Acknowledgments}

This paper was in part presented as a poster at the 19th Conference on Retroviruses and Opportunistic Infections, March 5-9, 2012, Seattle, WA, USA, Abstract \#941. We also acknowledge the immeasurable efforts of our study nurses, doctors, counselors, administrators, visiting residents, ID fellows, MHS student interns at the GF Jooste Hospital, Manenberg, Cape Town, South Africa. This work was partially supported by the National Institute of Allergy and Infectious Diseases, United States National Institutes of Health, R01 AI 5535901 (REC) and K23 068582-01 (JBN).

\section{Disclosure}

The authors report no conflicts of interest in this work.

\section{References}

1. Badri M, Wilson D, Wood R. Effect of highly active antiretroviral therapy on incidence of tuberculosis in South Africa: a cohort study. Lancet. 2002;359:2059-2064.

2. Miranda A, Morgan M, Jamal L, et al. Impact of antiretroviral therapy on the incidence of tuberculosis: the Brazilian experience, 1995-2001. PLoS One. 2007;2:e826.

3. Abdool Karim SS, Naidoo K, Grobler A, Padayatchi N, et al. Timing of initiation of antiretroviral drugs during tuberculosis therapy. $N$ Engl J Med. 2010;362(8):697-706.

4. Blanc FX, Sok T, Laureillard D, et al. CAMELIA (ANRS 1295-CIPRA KH001) Study Team. Earlier versus later start of antiretroviral therapy in HIV-infected adults with tuberculosis. N Engl J Med. 2011;365(16): 1471-1481.

5. Havlir DV, Kendall MA, Ive P, et al. Timing of antiretroviral therapy for HIV-1 infection and tuberculosis. $N$ Engl J Med. 2011;365(16): 1482-1491.

6. Nachega JB, Chaisson RE, Goliath R, et al. Randomized controlled trial of trained patient-nominated treatment supporters providing partial directly observed antiretroviral therapy. AIDS. 2010;24:1273-1280.
7. Southern African HIV Clinicians Soceity. Antiretroviral Therapy in Adults, January 2008. South Afr J HIV Med. 2008:18-31. Available from: http://www.hivhotline.uct.ac.za/sahivsoc_guideline_ADULT. pdf. Accessed May 22, 2012.

8. Republic of South Africa Department of Health. National Tuberculosis Management Guidelines. South Africa Department of Health; 2009. Available from: http://familymedicine.ukzn.ac.za/Libraries/Guidelines_Protocols/TB_Guidelines_2009.sflb.ashx. Accessed May 22, 2012.

9. Schag CC, Heinrich RL, Ganz PA. Karnofsky performance status revisited: Reliability, validity, and guidelines. J Clin Oncology. 1984; 2:187-193

10. Meintjes G, Lawn SD, Scano F, et al. International Network for the Study of HIV-associated IRIS. Tuberculosis-associated immune reconstitution inflammatory syndrome: case definitions for use in resource-limited settings. Lancet Infect Dis. 2008;8(8):516-523.

11. Haddow LJ, Colebunders R, Meintjes G, et al; International Network for the Study of HIV-associated IRIS (INSHI). Cryptococcal immune reconstitution inflammatory syndrome in HIV-1-infected individuals: proposed clinical case definitions. Lancet Infect Dis. 2010;10(11):791-802.

12. Lehloenya R, Meintjes G. Dermatologic manifestations of the immune reconstitution inflammatory syndrome. Dermatol Clin. 2006;24: 549-570.

13. Ewing JA. Detecting alcoholism: The CAGE questionnaire. J Am Med Assoc. 1984;252:1905-1906.

14. Narita M, Ashkin D, Hollender ES, Pitchenik AE. Paradoxical worsening of tuberculosis following antiretroviral therapy in patients with AIDS. Am J Respir Crit Care Med. 1998;158:157-161.

15. Eshun-Wilson I, Havers F, Nachega JB, et al. Evaluation of paradoxical TB-associated IRIS with the use of standardized case definitions for resource-limited settings. J Int Assoc Physicians AIDS Care (Chic). 2010;9(2):104-108. Epub February 16, 2010.

16. Pepper DJ, Marais S, Maartens G, et al. Neurological manifestations of paradoxical tuberculsosis-associated immune reconstitution inflammatory syndrome: a case series. Clin Infec Dis. 2009;48:e96-e107.

17. Lawn S, Meinjtjes G. Pathogenesis and prevention of immune reconstitution disease during antiretroviral therapy. Expert Rev Anti Infect Ther. 2011;9(4):415-430.

18. Thompson MA, Mugavero MJ, Amico KR, et al. Guidelines for improving entry into and retention in care and antiretroviral adherence for persons with HIV: evidence-based recommendations from an International Association of Physicians in AIDS Care panel. Ann Intern Med. 2012;156:817-833.
Patient Preference and Adherence

\section{Publish your work in this journal}

Patient Preference and Adherence is an international, peer-reviewed, open access journal focusing on the growing importance of patient preference and adherence throughout the therapeutic continuum. Patient satisfaction, acceptability, quality of life, compliance, persistence and their role in developing new therapeutic modalities and compounds to

\section{Dovepress}

optimize clinical outcomes for existing disease states are major areas of interest. This journal has been accepted for indexing on PubMed Central. The manuscript management system is completely online and includes a very quick and fair peer-review system. Visit http://www.dovepress.com/ testimonials.php to read real quotes from published authors. 